\title{
Thermal Analysis of Laser Chemical Machining: Part I: Static Irradiation
}

\author{
Hamza Messaoudi1, Sandro Eckert1, Frank Vollertsen ${ }^{1,2}$ \\ ${ }^{1}$ BIAS-Bremer Institut für angewandte Strahltechnik, Bremen, Germany \\ ${ }^{2}$ Faculty of Production Engineering-Mechanical Engineering \& Process Engineering, University of Bremen, Bremen, Germany \\ Email: messaoudi@bias.de
}

How to cite this paper: Messaoudi, $\mathrm{H}$. Eckert, S. and Vollertsen, F. (2017) Thermal Analysis of Laser Chemical Machining: Part I: Static Irradiation. Materials Sciences and Applications, 8, 685-707. https://doi.org/10.4236/msa.2017.810049

Received: July 20, 2017

Accepted: September 2, 2017

Published: September 5, 2017

Copyright (c) 2017 by authors and Scientific Research Publishing Inc. This work is licensed under the Creative Commons Attribution International License (CC BY 4.0).

http://creativecommons.org/licenses/by/4.0/

\section{(c) (i) Open Access}

\begin{abstract}
The laser chemical machining is a non-conventional substractive processing method. It is based on the laser-activation of a material dissolution of metals in electrolyte ambient via local-induced temperature gradients and allows a gentle and smooth processing of especially temperature-sensitive metals. However, the material removal is characterized by a narrow process window and is restricted by occurring disturbances, which are supposed to be related to the localized electrolyte boiling. In order to control the removal quality and avoid disturbances, the correlation between the laser-induced temperatures and the resulting removal geometry has to be better understood. In this work an analytical modeling of the laser-induced temperatures at the surface of titanium based on a Green-function approach is presented. The main influencing factors (laser, electrolyte, material) as well as possible heat transfer into the electrolyte are included and discussed. To verify the calculated temperatures, single spot experiments are performed and characterized for titanium in phosphoric acid solution within laser irradiation of $1 \mathrm{~s}$. The correlation between the temperature distribution and the resulting removal geometry is investigated based on a spatial superposition. Thereby, the bottom limit temperature is found to range between $63^{\circ} \mathrm{C}$ and $70^{\circ} \mathrm{C}$ whereas the upper limit is related to the nucleate boiling regime. Based on the performed correlation an indicator is identified to predict the ruling removal regime and thereby to reduce the experimental expenditure.
\end{abstract}

\section{Keywords}

Laser Micro Machining, Laser Chemical Removal, Modeling,

Temperature, Process Stability, Titanium 


\section{Introduction}

Within the ever-increasing trend of miniaturization, traditional mechanical machining reaches more and more its performance limits due to the enhanced complexity and amount of micro-components as well as occurring size effects [1]. At the same time, non-conventional machining is quickly taking root in the production of especially metallic micro tools and components [2].

Among others, these include the laser chemical machining (LCM) that unifies the advantages of laser machining with its precise and localized energy deposition and the electrochemical machining with its smooth processing without significant thermal impacts [3]. Laser chemical machining is a further development of the hybrid laser-assisted electrochemical machining, in which the laser beam is coaxially positioned to the electrolyte jet [4]. Within this process the laser beam heats up the workpiece, which is immerged in a continuously pumped electrolyte [5]. Depending on the laser parameters such as the laser power and spot diameter, the induced temperature fields at the workpiece surface can change the electrochemical potential in a range within it the anodic material dissolution is activated and results thereby in the removal of the base material [6]. This laser-activated chemical dissolution was observed for different self-passivating metals, e.g. stainless steel and titanium alloys [7]. Within suitable process windows a gentle removal occurs without significant heat affected zones or a recast formation. This gentle processing represents the main advantage compared with the laser machining, in which micro-cracks, distortion and stress can result when using short laser pulses [8].

However, the dynamics of the laser light absorption, heat, chemical reactions, hydrodynamics and transport phenomena causes within a certain range of parameters a disturbance of material removal [9]. As Laser chemical machining is mainly a temperature-driven process, it was experimentally demonstrated that occurring disturbances are strongly related to the electrolyte boiling and the ensuing gas bubble formation [9] as well as to the electrolyte-metal combination [10]. Nevertheless, it is still a lack of knowledge about the direct correlation between the laser-induced temperatures and the resulting removal geometry.

Within this work, an analytical modeling of the laser-induced surface temperatures is presented based on a Green-function approach. It takes into account the main influencing factors (laser, electrolyte and material) as well as possible heat transfer into the electrolyte and is used to identify the influence of single process parameters on the temperature distribution. In addition, the removal properties are experimentally characterized in order to validate the modeling results. Therefore, single spot experiments are performed for titanium in phosphoric acid solution within laser irradiation of $1 \mathrm{~s}$. The correlation between the temperature distribution and the resulting removal geometry is investigated based on a spatial superposition. In dependence of laser power and beam diameter the starting temperature for a laser chemical removal as well as its upper limit temperature are determined. Furthermore, it is shown that once validated 
the presented model can be used to predict the process window for a disturbance-free LCM-process and there by helps reducing the experimental expenditure.

\section{Process Fundamentals}

The laser irradiation is used in laser chemical machining as a localized and selective heat source that can induce suitable thermal impact for the activation of heterogeneous chemical reaction between a liquid ambient and a metallic surface and results in a temperature-induced electrochemical etching [6]. At suitable parameter settings the metal dissolution occurs under the formation of hydrogen and water soluble metallic salts following the chemical reaction (see Figure 1):

$$
\mathrm{Me}+2 \mathrm{H}^{+} \rightarrow \mathrm{Me}^{2+}+\mathrm{H}_{2} \uparrow
$$

In laser chemical machining, the workpiece surface is in a direct contact to the electrolytic solution. In consequence of its heat impact the laser beam can induce or enhance reactions at the metal-liquid interface via changes in the electrochemical Nernst potential. The locally induced temperature gradients result in the generation of a thermobattery allowing a current flow within the metal between the center of the incident laser light and its periphery. Despite the low generated electromotive forces (some $0.1 \mathrm{~V}$ for a temperature rise of $100 \mathrm{~K}$ ) the electric field strengths are very high due to the small battery dimensions [6]. Thus, self-passivating metals lose their natural passivation property allowing then the dissolution of the base material [3].

Within the LCM-process the laser induced-temperatures define both, the proton activity within the redox-reaction and the electrochemical potential at the workpiece surface [11]. It is therefore plain that certain threshold temperatures are required in order to realize a material removal above the background etching rate (some $10^{-9} \mathrm{~m} / \mathrm{s}$ ). Thereby, the laser-induced temperatures depend on different factors that can be divided in:

1) Laser characteristics: laser power, irradiation duration, intensity distribution, spot size and feed velocity.

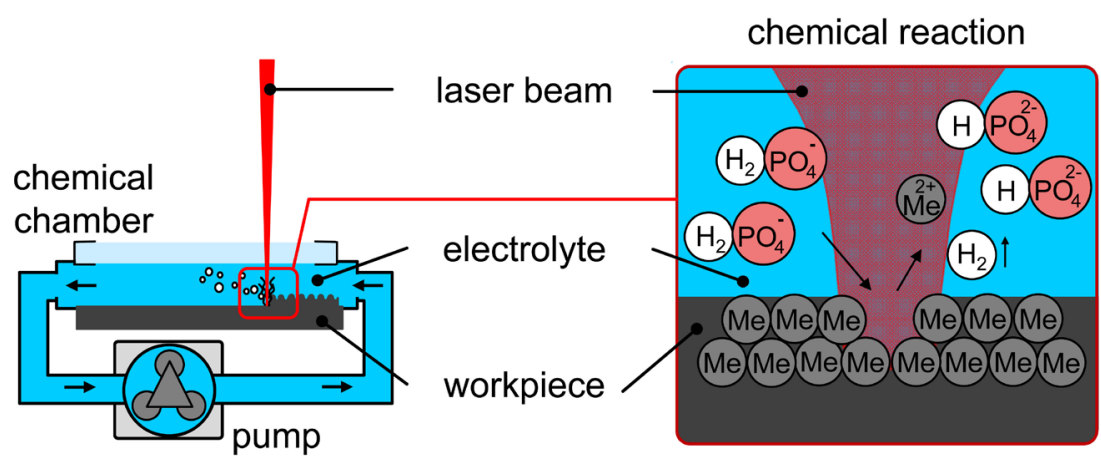

Eckert 2017

BIAS ID 171249

Figure 1. Schematic illustration of the principles of the laser chemical removal of metals. Here, phosphoric acid is taken exemplarily as the electrolyte solution. 
2) Material properties: wavelength-dependent absorption coefficient, chemical composition, thermal diffusivity, specific heat, density...

3) Electrolyte properties: acidic/basic solution, concentration, layer thickness, wavelength-dependent transmission coefficient.

Beside the temperature, the electrochemical potential is also depending on the chemical activity of the dissolved metal ions and on the mass transport limitation [3]. Latter one is mainly determining the removal speed within the aqueous electrolytes. Further, the convective flow represents also an important factor by determining the transport of reaction products as well as the provision and exchange of reactants. An increased convection can enhance the reaction rates by several orders of magnitude. At high laser intensities an electrolyte boiling can occur resulting on the formation of vapor gas bubble. Among others, Mehrafsun et al. [9] and Yavas et al. [12] have reported that the formed bubbles result in removal disturbances that impede the controllability of the LCM process. Therefore, it is recommended to avoid electrolyte boiling.

\section{Methodology}

\subsection{Model Assumptions}

As already mentioned, the laser irradiation has the function of thermally activate the chemical etching reaction. Because of the high number of influence factors as well as the complex interaction nature (chemically, physically and flow dynamics) it is still a lack of knowledge about the mechanisms occurring during LCMprocess.

The laser radiation propagates throughout the etchant solution, is absorbed at the workpiece surface, induces a temperature distribution that define the area and properties of the chemical dissolution reaction and thereby the quality of the material removal. Therefore, a determination of the temperature distribution over the workpiece surface would help to understand the influences of the main process parameters. To build up a theoretical description of the surface temperature following assumptions have been made:

1) The laser beam - as the heat source-is a $\mathrm{TEM}_{00}$-mode with a Gaussian intensity distribution

$$
I(x, y)=I_{0} \cdot \mathrm{e}^{\left[\left(\frac{x}{r_{x}}\right)^{2}+\left(\frac{y}{r_{y}}\right)^{2}\right]}
$$

where $I_{0}=P_{a b s} / A$ with $P_{a b s}$ is the absorbed laser power and $A$ is the laser beam area at the workpiece surface, $A=\pi r_{x} r_{y}$ and $r_{x}=r_{y}$.

2) The workpiece/laser beam is moving with a constant speed $V$ and in $x$-direction. In this work the feed velocity $V=0$, as only the case of a static irradiation is studied.

3) The material is supposed to be isotropic with temperature-independent properties.

4) Phase changes do not occur. On the one hand laser melting cannot occur at the applied laser powers and on the other hand the formation of metallic salt lay- 
ers is neglected.

5) The laser power is affected by the transmission coefficient $\tau_{E}$ that describes the power loss during the propagation throughout the etchant solution and by the absorption coefficient $\alpha_{a b s}$ of the metallic material. Both coefficients are assumed to be constant and temperature-independent. The absorbed laser power $P_{a b s}$ is then described as:

$$
P_{a b s}=P_{L} \cdot \alpha_{a b s} \cdot \tau_{E}
$$

6) The thermal interaction takes place only between laser beam and workpiece. Additional contributions, such as the heat of reaction, are neglected.

7) Heat transfer into the etchant solution is considered. The heat equation includes heat loss rates dependent on constant heat transfer coefficients of the electrolyte.

8) For the description of the heat equation a rectangular coordinate system is used. This is fixed in the workpiece, where the origin is directly beneath the beam center, $x$ - $y$-plane is the workpiece surface and the positive $z$-axis points into the workpiece. The laser beam interacts with the workpiece at $z=0$. All relevant modeling parameters are listed in Table A1 (see Supplementary Material).

\subsection{Green's Function Based Model}

The interaction between laser irradiation and metallic surface is assumed to be dominated by conduction during the electron-lattice heating. The conduction is related to the thermal diffusivity $D$, the volumetric heat capacity $C_{p}$ and the material density $\rho$. The resulting temperature distribution $T$ in the material is associated to the power density $Q$ through the diffusion equation:

$$
\frac{\partial T}{\partial t}=D\left(\frac{\partial^{2} T}{\partial x^{2}}+\frac{\partial^{2} T}{\partial y^{2}}+\frac{\partial^{2} T}{\partial z^{2}}\right)-\frac{Q}{\rho C_{p}}
$$

Here, $Q$ represents the contribution of the heat source (laser beam) and can be described as:

$$
Q=\frac{P_{a b s}}{2 \pi r^{2}} \cdot \mathrm{e}^{-\frac{(x-v t)^{2}+y^{2}}{2 r^{2}}} \cdot \mathrm{e}^{-\alpha z}
$$

The temperature rise $T(x, y, z, t)$ is valid for $x>-\infty, y<\infty, 0 \leq z \leq \infty$ and $t>0$ and follows the boundary conditions (see Figure 2):

$$
\begin{aligned}
& T=0 \text { at } t=0, T \rightarrow 0 \text { for } x, y \rightarrow \pm \infty \\
& T \rightarrow 0 \text { for } z \rightarrow \infty, \frac{\partial T}{\partial t}=\frac{H}{\kappa} T \text { at } z=0
\end{aligned}
$$

For a simplified mathematical treatment a dimensionless formulation of Equation (4) has to be provided. Therefore, following dimensionless variables were defined:

$$
X=\frac{x}{r}, Y=\frac{y}{r}, Z=\frac{Z}{r}, \tau=\frac{2 D t}{r^{2}}, \mu=\frac{v \cdot r}{D}, \alpha=\frac{r}{l}, \Theta=\frac{H \cdot r}{\kappa}
$$




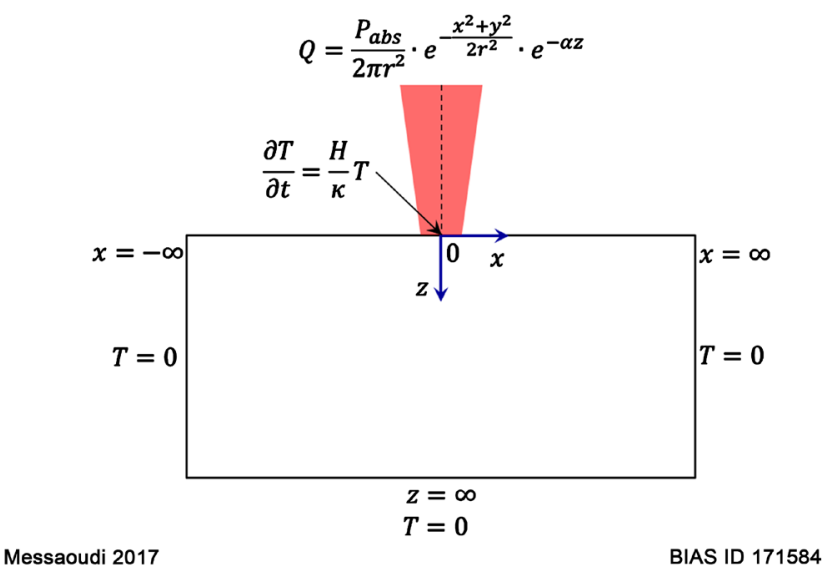

Figure 2. Schematic of the laser heating with the related boundary conditions. For a simplified illustration only the x-z-plane is shown.

and

$$
\Psi=\frac{T}{\Delta T^{\prime}} \text { with } \Delta T=\frac{P_{a b s}}{4 \sqrt{\pi} \kappa r}
$$

The dimensionless heat equation can be then formulated as [13]:

$$
\frac{\partial \Psi}{\partial t}=\frac{\partial^{2} \Psi}{\partial X^{2}}+\frac{\partial^{2} \Psi}{\partial Y^{2}}+\frac{\partial^{2} \Psi}{\partial Z^{2}}-\mu \frac{\partial \Psi}{\partial X}-\frac{2 \alpha}{\sqrt{\pi}} \mathrm{e}^{-X^{2}-Y^{2}-\alpha Z}
$$

where following boundary conditions are valid:

$$
\begin{aligned}
& \Psi=0 \text { at } \tau=0, \Psi \rightarrow 0 \text { for } X, Y \rightarrow \pm \infty \\
& \Psi \rightarrow 0 \text { for } Z \rightarrow \infty, \frac{\partial \Psi}{\partial \tau}=\Theta \Psi \text { at } Z=0
\end{aligned}
$$

The solution of the dimensionless temperature distribution at the workpiece surface $(Z=0)$ is given by:

$$
\begin{aligned}
\Psi(X, Y, 0, \tau)= & \int_{0}^{\tau} \int_{-\infty}^{\infty} \int_{-\infty}^{\infty} \int_{0}^{\infty} G\left(X, Y, 0, \tau, X^{\prime}, Y^{\prime}, Z^{\prime}, \tau^{\prime}\right) \\
& \times \frac{2 \alpha}{\sqrt{\pi}} \mathrm{e}^{-X^{\prime 2}-Y^{\prime 2}-\alpha Z^{\prime}} \mathrm{d} Z^{\prime} \mathrm{d} Y^{\prime} \mathrm{d} X^{\prime} \mathrm{d} \tau^{\prime}
\end{aligned}
$$

Here, the general solution of the Green-function $G\left(X, Y, 0, \tau, X^{\prime}, Y^{\prime}, Z^{\prime}, \tau^{\prime}\right)$ is:

$$
G=\frac{1}{4\left[\pi\left(\tau-\tau^{\prime}\right)\right]^{3 / 2}} e^{\frac{-\left(X-X^{\prime}\right)^{2}+\left(Y-Y^{\prime}\right)^{2}+\left(Z-Z^{\prime}\right)^{2}}{4\left(\tau-\tau^{\prime}\right)}}
$$

In accordance with Carslaw and Jaeger [14], the Green-function for the 3Dcase can be described as follows:

$$
\begin{aligned}
G= & \frac{1}{\left[4 \pi\left(\tau-\tau^{\prime}\right)\right]^{\frac{3}{2}}} \mathrm{e}^{-\left[\frac{\left(X-X^{\prime}-\mu\left(\tau-\tau^{\prime}\right)\right)^{2}+\left(Y-Y^{\prime}\right)^{2}}{4\left(\tau-\tau^{\prime}\right)}\right]} \times\left\{\mathrm{e}^{\frac{-\left(Z-Z^{\prime}\right)^{2}}{4\left(\tau-\tau^{\prime}\right)}}+\mathrm{e}^{\frac{-\left(Z+Z^{\prime}\right)^{2}}{4\left(\tau-\tau^{\prime}\right)}}\right. \\
& \left.-\sqrt{4 \pi\left(\tau-\tau^{\prime}\right) \theta} \cdot \mathrm{e}^{\theta^{2}\left(\tau-\tau^{\prime}\right)+\theta\left(Z+Z^{\prime}\right)} \cdot \operatorname{erfc}\left[\frac{Z+Z^{\prime}}{2 \sqrt{\tau-\tau^{\prime}}}+\theta \sqrt{\tau-\tau^{\prime}}\right]\right\}
\end{aligned}
$$


Using the substitution $\phi=\tau-\tau^{\prime}$ and taking into account the velocity related term $\mu$; the dimensionless Equation (Equation (7)) at $Z=0$ can be transformed into:

$$
\begin{aligned}
\Psi= & \frac{2 \alpha}{\sqrt{\pi}} \int_{0}^{\tau} \int_{-\infty}^{\infty} \int_{-\infty}^{\infty} \int_{0}^{\infty} \frac{1}{[4 \pi \phi]^{\frac{3}{2}}} \mathrm{e}^{-\left[\frac{\left(X-X^{\prime}-\mu \phi\right)^{2}+\left(Y-Y^{\prime}\right)^{2}}{4 \phi}\right]} \cdot \mathrm{e}^{\frac{-\left(Z-Z^{\prime}\right)^{2}}{4 \phi}} \\
& \cdot \mathrm{e}^{-X^{\prime 2}-Y^{\prime 2}-\alpha Z^{\prime}} \mathrm{d} Z^{\prime} \mathrm{d} Y^{\prime} \mathrm{d} X^{\prime} \mathrm{d} \phi \\
& +\frac{2 \alpha}{\sqrt{\pi}} \int_{0}^{\tau} \int_{-\infty}^{\infty} \int_{-\infty}^{\infty} \int_{0}^{\infty} \frac{1}{[4 \pi \phi]^{\frac{3}{2}}} \mathrm{e}^{-\left[\frac{\left(X-X^{\prime}-\mu \phi\right)^{2}+\left(Y-Y^{\prime}\right)^{2}}{4 \phi}\right]} \cdot \mathrm{e}^{\frac{-\left(Z+Z^{\prime}\right)^{2}}{4 \phi}} \\
& \cdot \mathrm{e}^{-X^{\prime 2}-Y^{\prime 2}-\alpha Z^{\prime}} \mathrm{d} Z^{\prime} \mathrm{d} Y^{\prime} \mathrm{d} X^{\prime} \mathrm{d} \phi-\frac{2 \alpha}{\sqrt{\pi}} \int_{0}^{\tau} \int_{-\infty}^{\infty} \int_{-\infty}^{\infty} \int_{0}^{\infty} \frac{1}{[4 \pi \phi]^{\frac{3}{2}}} \mathrm{e}^{-\left[\frac{\left(X-X^{\prime}-\mu \phi\right)^{2}+\left(Y-Y^{\prime}\right)^{2}}{4 \phi}\right]} \\
& \cdot\left\{\mathrm{e}^{\frac{-\left(Z-Z^{\prime}\right)^{2}}{4 \phi}}+\mathrm{e}^{\frac{-\left(Z+Z^{\prime}\right)^{2}}{4 \phi}}-\sqrt{4 \pi \phi} \theta \cdot \mathrm{e}^{\theta^{2} \phi+\theta\left(Z+Z^{\prime}\right)} \cdot \operatorname{erfc}\left[\frac{Z+Z^{\prime}}{2 \sqrt{\phi}}+\theta \sqrt{\phi}\right]\right\} \\
& \cdot \mathrm{e}^{-X^{\prime 2}-Y^{\prime 2}-\alpha Z^{\prime}} \mathrm{d} Z^{\prime} \mathrm{d} Y^{\prime} \mathrm{d} X^{\prime} \mathrm{d} \phi
\end{aligned}
$$

In Equation (10) the first two integrals represent the lossless heat equation, whereas the third term includes the heat losses when considering heat transfer into the electrolyte (i.e. $H>0$ ). This formulation is in good agreement with the work of Yung et al. [15], in which a similar approach was used.

With help of the closed-form approximation of the error function, described in [16]:

$$
\mathrm{e}^{x} \cdot \operatorname{erfc}(x) \approx \frac{a}{(a-1) \sqrt{\pi x^{2}}+\sqrt{\pi x^{2}+a}}
$$

where $a=\pi /(\pi-2)$, the surface temperature rise $T(x, y, 0, t)$ can be finally simplified and described as:

$$
\begin{aligned}
T= & \frac{P \cdot \alpha_{A b s} \cdot \tau_{E}}{4 \pi \cdot \kappa \cdot l} \cdot \int_{0}^{\tau} \frac{1}{1+4 \phi} \cdot \frac{a}{(a-1) \sqrt{\pi \alpha^{2} \phi}+\sqrt{\pi \alpha^{2} \phi+a^{2}}} \cdot \mathrm{e}^{-\left[\frac{(X-\mu \phi)^{2}+Y^{2}}{1+4 \phi}\right]} \mathrm{d} \phi \\
& -\frac{P \cdot \alpha_{A b s} \cdot \tau_{E}}{4 \pi \cdot \kappa \cdot l} \cdot \theta \int_{0}^{\tau} \frac{1}{1+4 \phi} \mathrm{e}^{\left.-\frac{(X-\mu \phi)^{2}+Y^{2}}{1+4 \phi}\right]} \\
& \cdot \int_{0}^{\infty} \frac{a}{(a-1) \sqrt{\pi\left(\frac{Z^{\prime}}{4 \phi}+\Theta^{2} \phi+\Theta Z^{\prime}\right)}+\sqrt{\pi\left(\frac{Z^{\prime}}{4 \phi}+\Theta^{2} \phi+\Theta Z^{\prime}\right)+a^{2}}} \\
& \cdot \mathrm{e}^{-\frac{Z^{\prime 2}}{4 \phi}} \cdot \mathrm{e}^{-\alpha Z^{\prime}} \mathrm{d} Z^{\prime} \mathrm{d} \phi
\end{aligned}
$$

\subsection{Experimental}

As laser source a cw-fiber laser JK400 (from JK Lasers) was used. Its $\mathrm{TEM}_{00}$ $\mathrm{cw}$-laser radiation of $1080 \mathrm{~nm}$ is focused by a telecentric $\mathrm{f}$-theta optic and guided using the galvanometer scanning system Raylase Superscan III-15 to the surface. 
Using an inverse telescope, the laser beam diameter and thus the focal spot size can be varied. Within the performed investigations the laser spot diameters 30.5 $\mu \mathrm{m}$ and $109 \mu \mathrm{m}$ were applied. As sample material rolled titanium ( $\mathrm{Ti}$ 3.7024) with a thickness of $0.8 \mathrm{~mm}$ was used. The Ti-workpiece was placed in a closed liquid-phase etching chamber, where a 5 molar $(28.7 \%$ vol.) phosphoric acid $\left(\mathrm{H}_{3} \mathrm{PO}_{4}\right)$ was pumped as a cross-jet through a $25 \mathrm{~mm} \times 2 \mathrm{~mm}$ cross-section with velocity $v_{f}$ of $2 \mathrm{~m} / \mathrm{s}$. The electrolyte layer between workpiece and protective glass has a thickness of $2 \mathrm{~mm}$. A detailed description of the used setup can be found in [17].

Depending on laser power and spot diameter arrays of $4 \times 4$ single irradiation spots were structured, while the irradiation time was kept constant at $1 \mathrm{~s}$. The main process parameters as well as the properties of the used material and electrolyte are listed in Table 1 . The removal cavities (depth and diameters) were recorded and characterized using a 3D-laser confocal microscope (VHX970-Keyence). For a statistic evaluation five different irradiations spots per used laser power were measured, while 3 to 5 height profiles were captured for every single cavity.

\section{Results}

\subsection{Modeled Influence of Laser Parameters}

To study the influence of laser parameters we consider the case of an absent heat transfer into the etchant solution. Here, $\Theta=0$ and $\partial \psi / \partial z=0$ at $Z=0$. Thus, the temperature rise in Equation (12) can be reduced to its first term:

$$
T(X, Y, 0, \phi)=\frac{P \cdot \alpha_{A b s} \cdot \tau_{E}}{4 \pi \kappa l} \int_{0}^{\tau} \frac{1}{1+4 \phi} \mathrm{e}^{-\frac{X^{2}+Y^{2}}{1+4 \phi}} \frac{a}{(a-1) \sqrt{\pi \alpha^{2} \phi}+\sqrt{\pi \alpha^{2} \phi+a^{2}}} \mathrm{~d} \phi
$$

Table 1. List of process parameters used for both, modeling and experimental investigation.

\begin{tabular}{cccc}
\hline & Properties & Unit & Value \\
\hline \multirow{2}{*}{ Titanium (3.7024) } & Thermal diffusivity $D$ & $\mathrm{~m}^{2} / \mathrm{s}$ & $6.8 \times 10^{-6}$ \\
& Thermal conductivity $\mathrm{K}$ & $\mathrm{W} /(\mathrm{m} \cdot \mathrm{K})$ & 21 \\
& Absorption coeff. at NIR $\alpha_{\mathrm{abc}}$ & - & 0.4 \\
\hline Waser beam & Wavelength $\lambda$ & $\mathrm{nm}$ & 1080 \\
& Focus spot diameter $d_{\text {spot }}$ & $\mu \mathrm{m}$ & $30.5,68,109$ \\
& Irradiation time $t_{L}$ & $\mathrm{~s}$ & 1 \\
& Laser power $P_{L}$ & $\mathrm{~W}$ & $0 \cdots 20$ \\
\hline \multirow{3}{*}{ Electrolyte } & Solution & - & $\mathrm{H}_{3} \mathrm{PO}_{4}$ \\
& Concentration & $\mathrm{mol} / 1$ & 5 \\
& Boiling temperature $T_{\text {Boiling }}$ & ${ }^{\circ} \mathrm{C}$ & 104 \\
& Layer thickness & $\mathrm{Mm}$ & 1 \\
& Transmission coefficient $\tau_{E}$ & - & 0.96 \\
& Flow speed & $\mathrm{m} / \mathrm{s}$ & 2 \\
\hline
\end{tabular}




\subsubsection{Influence of Laser Power}

In Figure 3 the resulting temperatures at the surface of titanium around the laser spot center are shown exemplarily for $d_{\text {spot }}=30.5 \mu \mathrm{m}$. As expected from Equation (13), the surface temperature is mainly determined by the laser power.

For a beam diameter of $30.5 \mu \mathrm{m}$, the peak temperature as well as the width of distribution increase linearly with the laser power. Thereby, the boiling temperature of the used phosphoric acid $\left(T_{\text {Boiling }}=104^{\circ} \mathrm{C}\right)$ can be achieved at laser powers of about $1 \mathrm{~W}$. Thus, higher laser powers are not recommended as the electrolyte boiling is assumed to affect the quality of LCM because of occurring gas bubble formation [9].

\subsubsection{Influence of Laser Spot Size}

Figure 4(a) shows the influence of focus beam diameter $d_{\text {spot }}$ on the resulting temperature distribution at a constant laser power of $2 \mathrm{~W}$. Here, the increase in $d_{\text {spot }}$ from $30.5 \mu \mathrm{m}$ to $109 \mu \mathrm{m}$ results in a decrease of the peak temperature rise from $190^{\circ} \mathrm{C}$ down to $67^{\circ} \mathrm{C}$. This is due to the lower power density at a bigger spot area $\left(274 \mathrm{~kW} / \mathrm{cm}^{2}\right.$ vs $\left.21.5 \mathrm{~kW} / \mathrm{cm}^{2}\right)$. In Figure 4 (b) it can be seen that the temperature rise becomes faster when increasing the laser spot diameter. For a power density of $50 \mathrm{~kW} / \mathrm{cm}^{2}$, the peak temperatures amount $51^{\circ} \mathrm{C}, 88^{\circ} \mathrm{C}$ and $130^{\circ} \mathrm{C}$ with spot diameters of $30.5 \mu \mathrm{m}, 68 \mu \mathrm{m}$ and $109 \mu \mathrm{m}$, respectively. Moreover the electrolyte boiling $\left(T_{\text {Boiling }}=104^{\circ} \mathrm{C}\right)$, as an assumed critical temperature, can be achieved at a power density of $137 \mathrm{~kW} / \mathrm{cm}^{2}$ with $d_{\text {spot }}=30.5 \mu \mathrm{m}$ and 38 $\mathrm{kW} / \mathrm{cm}^{2}$ with $d_{\text {spot }}=109 \mu \mathrm{m}$. Thus, it is recommended to avoid exceeding these laser power densities in order realize a disturbance-free LCM.

\subsection{Modeled Influence of Heat Transfer into the Electrolyte}

Within the LCM process occurring heat losses are mainly related to the heat transfer into the electrolyte. It has to be noticed that the presented modeling

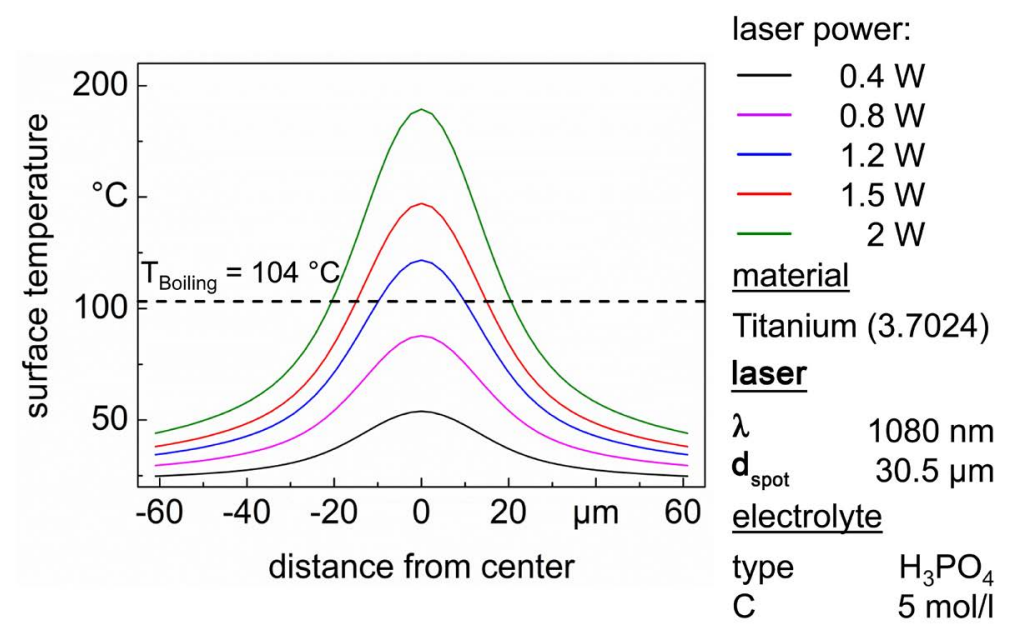

Messaoudi 2017

BIAS ID 171585

Figure 3. Temperature distribution on the surface of titanium at a distance $x_{0}$ from the center of a laser spot $\left(d_{\text {spot }}=30.5 \mu \mathrm{m}\right)$ calculated using Equation (13). 


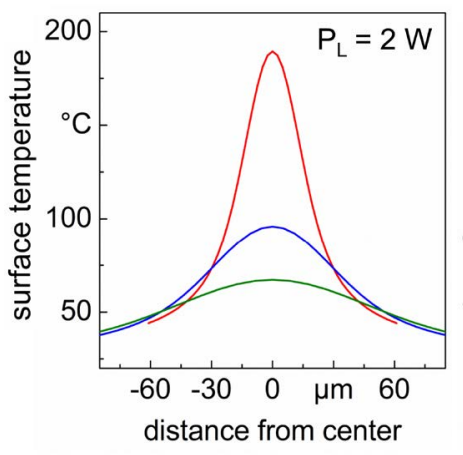

Messaoudi 2017

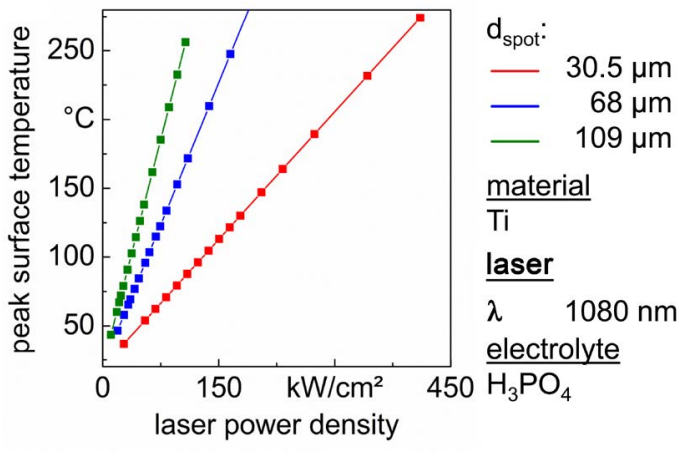

BIAS ID 171586

Figure 4. Calculated influence of the laser beam diameter on surface temperature distribution on titanium at a constant laser power $P_{L}=2 \mathrm{~W}$ (a) and on the peak surface temperature $T_{\text {model,peak }}$ in dependence of the applied laser power density (b).

enables a simplified consideration of heat transfer using constant heat transfer coefficients. As the laser spot size, which defines the width of the interaction zone, ranges between $30.5 \mu \mathrm{m}$ and $109 \mu \mathrm{m}$ in diameter, we have to consider heat transfer coefficients representing enforced heat convection in the micro range. Thereby, the case of water flows in a micro pipe has been chosen as a reference. Depending on the electrolyte temperature two different heat transfer coefficients $H$ were defined [18]:

- $\quad H=50.000 \mathrm{~W} /\left(\mathrm{m}^{2} \cdot \mathrm{K}\right)$ for the case water boiling. It was applied for temperature distributions with $T_{\text {model,peak }}>90^{\circ} \mathrm{C}$. This is based on the work of De Silva et al. [5], in which it was shown that the risk of an electrolyte boiling is extremely enhanced for surface temperatures greater than $90^{\circ} \mathrm{C}$.

- $H=3.000 \mathrm{~W} /\left(\mathrm{m}^{2} \cdot \mathrm{K}\right)$ representing an enforced convection within a moderate water flow. This value was applied for temperature distributions with $T_{\text {mo- }}$ del,peak $<90^{\circ} \mathrm{C}$.

Figure 5 shows the influence of considered heat transfer on the modeled peak temperature line for different laser spot diameters. Here, it can be distinguished between the heat transfer before and after the electrolyte boiling. The heat transfer caused by a moderate flow for temperatures $<90^{\circ} \mathrm{C}$ is negligible. The temperature differences compared to the lossless case $\left(H=0 \mathrm{~W} / \mathrm{m}^{2} \cdot \mathrm{K}\right)$ amount between $0.1 \mathrm{~K}$ and $0.4 \mathrm{~K}$. In contrast, for the case of occurring electrolyte boiling (assumed for $T>90^{\circ} \mathrm{C}$ ) the heat transfer into the etchant solution increases. With the change of heat transfer coefficient from 3.000 to $50.000 \mathrm{~W} / \mathrm{m}^{2} \cdot \mathrm{K}$ for $T_{\text {model,peak }}>90^{\circ} \mathrm{C}$ the deviation from the lossless case becomes clear. Thereby, it can be seen in Figure 5 that heat losses increase with the applied laser power density and the laser spot diameter. For peak temperatures up to $200^{\circ} \mathrm{C}$, the measured decrease ranges between $1.5 \mathrm{~K}$ and $3 \mathrm{~K}$ at a spot diameter of $30.5 \mu \mathrm{m}$, whereas this decrease lies between $4 \mathrm{~K}$ and $10 \mathrm{~K}$ at $d_{\text {spot }}=109 \mu \mathrm{m}$.

In general, it can be stated that for surface temperatures between $20^{\circ} \mathrm{C}$ and $100^{\circ} \mathrm{C}$ the heat transfer into the electrolyte during the LCM can be neglected. 

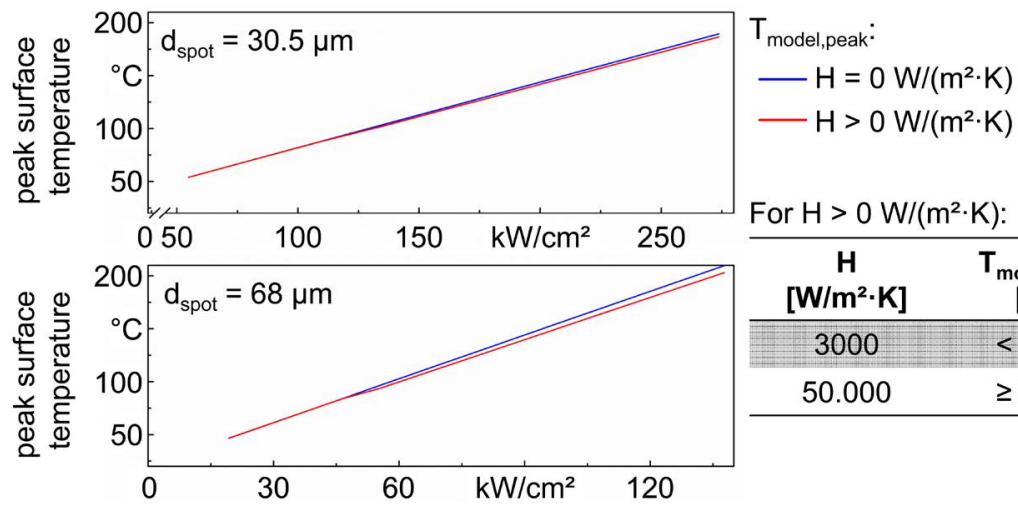

\begin{tabular}{cc}
\hline $\begin{array}{c}H \\
{\left[\mathrm{~W} / \mathrm{m}^{2} \cdot \mathrm{K}\right]}\end{array}$ & $\begin{array}{c}\mathrm{T}_{\text {model,peak }} \\
{\left[{ }^{\circ} \mathrm{C}\right]}\end{array}$ \\
\hline 3000 & $<90^{\circ} \mathrm{C}$ \\
\hline 50.000 & $\geq 90^{\circ} \mathrm{C}$ \\
\hline
\end{tabular}

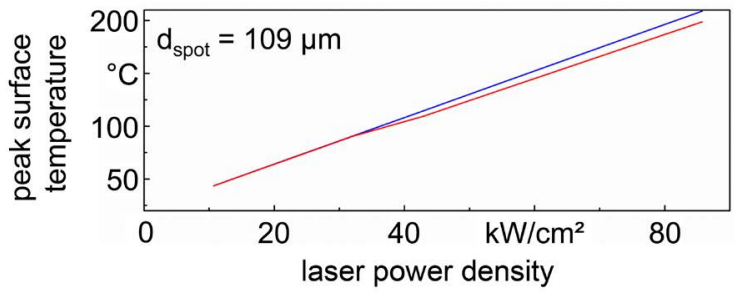

Messaoudi 2017

BIAS ID 171588

Figure 5. Peak surface temperature line in dependence of considered heat losses into the electrolyte for different laser beam spot diameters.

\subsection{Experimental Verification}

\subsubsection{Removal Characteristics}

The influence of the laser power on the resulting surface modification on titanium after an irradiation time of $1 \mathrm{~s}$ is exemplarily illustrated in Figure 6 for $d_{\text {spot }}=30.5 \mu \mathrm{m}$. The surface modification obtained with $d_{\text {spot }}=109 \mu \mathrm{m}$ are included within the supplementary material (Figure A1).

As can be seen, a detectable material removal (depth $>1 \mu \mathrm{m}$ ) occurs first at laser power of around $0.65 \mathrm{~W}$. For $0.7 \mathrm{~W}<P_{L}<1.1 \mathrm{~W}$ the removal rates increase with the laser power. Here, a bell-like removal shape is observed, which indicates a disturbance-free processing and suitable induced surface temperatures. From $P_{L}>1.1 \mathrm{~W}$ the cavity profile changes to a W-like shape, in which the maximum removal depth is shifted from the center to the outer flanks. A further increase of laser power (especially from $P_{L}>1.4 \mathrm{~W}$ ) leads to a change of the removal behavior. In this regime an additional material deposition, as seen in the height profiles in Figure 6, can be observed in the disturbance region.

Because of occurring electrolyte turbulences these mushroom-like structures are sometimes locally shifted from the cavity center. The same three regimes were also observed with $d_{\text {spot }}=109 \mu \mathrm{m}$. Here, a detectable removal in titanium was obtained first at $P_{L}=2.6 \mathrm{~W}$. The removal retains its bell-like shape up to laser powers of $4.6 \mathrm{~W}$. At higher laser power the removal is then disturbed as the mushroom-like structures appear.

In a previous work a detailed EDX-analysis of the chemical composition of the different cavities was performed [17]. While only the $K_{\alpha}$ and $K_{\beta}$ peaks of titanium were detected within the disturbance-free removal regime, the occurring removal disturbances were characterized by the appearance of additional phosphor 


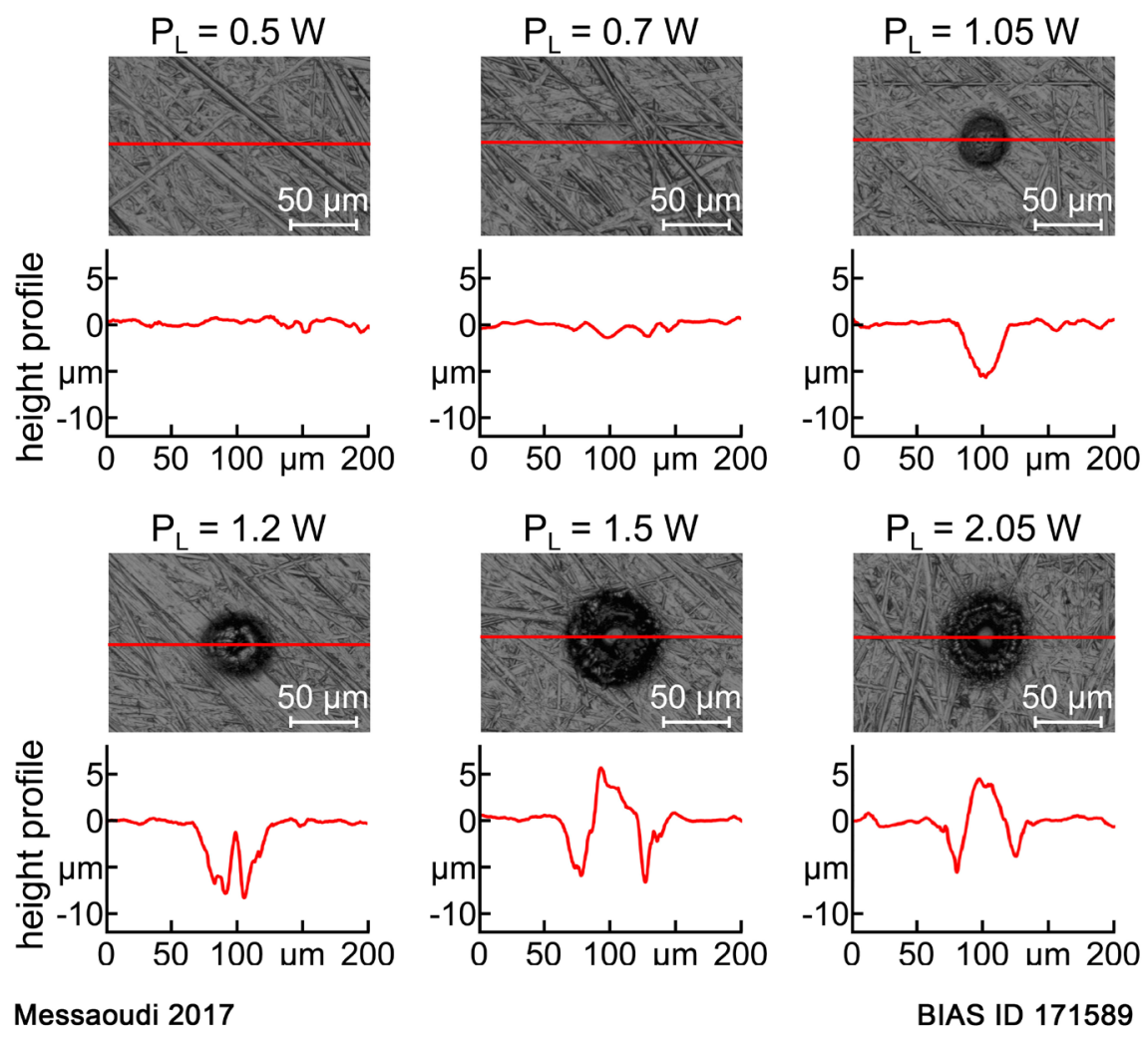

Figure 6. Microscopic images of the removal spots and their height profiles in dependence of the applied laser power after a $1 \mathrm{~s}$-irradiation with a $30.5 \mu \mathrm{m}$ laser spot.

and oxygen peaks. The formation of both titanium oxide and titanium phosphate is supposed to be strongly related to the thermal interaction of a formed boiling gas bubble with the laser-induced convection dynamic in the removal cavity, so that an intense deposition of titanium-phosphate is located more at the cavity center than at the outer flanks. A detailed discussion of the appearance of the mushroom-like structures can be found in [17].

\subsubsection{Removal Depth}

With respect to the ruling process regime the resulting removal depths were measured at the center of the removed cavity in the disturbance-free regime and at the flanks of the $\mathrm{W}$-like cavity in the disturbed regime. Figure 7 depicts the removal depths obtained with both spot diameters $30.5 \mu \mathrm{m}$ and $109 \mu \mathrm{m}$ in dependence of the applied laser power. The results reveal that the removal depths can be assigned directly to the different removal regimes. During the disturbance-free regime (Regime II) the removal depth increases linearly with the laser power up to values of $11 \mu \mathrm{m}$ (with $d_{\text {spot }}=30.5 \mu \mathrm{m}$ ) and $7 \mu \mathrm{m}$ (with $d_{\text {spot }}=109$ $\mu \mathrm{m}$ ), whereby the deviations were measured to range between $0.1 \mu \mathrm{m}$ and 0.7 $\mu \mathrm{m}$. In contrast, the transition to the disturbed regime is characterized in the one hand by a shifting of the removal depth from the center to the outer sides (see Figure 6). In the other hand the occurring disturbances are reflected on the enhanced deviations of the measured depth. These lie between $1.2 \mu \mathrm{m}$ and $2.5 \mu \mathrm{m}$. 


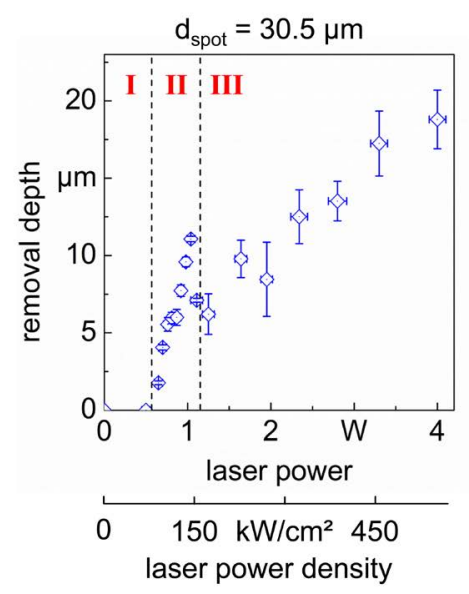

Messaoudi 2017

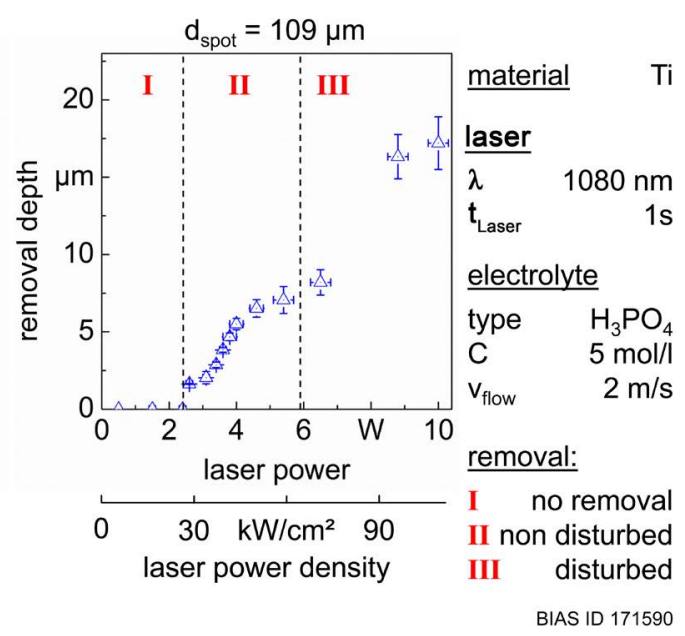

Figure 7. Measured removal depth in dependence of the applied laser power (density) obtained with both laser spot diameters $30.5 \mu \mathrm{m}$ and $109 \mu \mathrm{m}$. The deviation in power is due to the measurement uncertainty of the powermeter, while the deviation in depth is related to the experimental and analysis methods.

Moreover, it is observed that the depth is briefly reduced before it continues to grow with a slower slope. At the same time the width as well as the volume of the accumulated metallic salts increase. Figure 7 depicts clearly that the formed mushroom-like structures (within regime III) grow linearly with the laser power.

\subsubsection{Cavity Diameters}

To enable a direct correlation between the resulting removal geometry and the laser-induced temperature distribution at the workpiece surface a spatial superposition of both is required. Therefore, the diameter of the observed removal cavities, referred to as $D_{\text {outer }}$, was measured for the disturbance-free regime. Here, the center of the incident laser beam represents the origin of the coordinate system at workpiece surface. Besides, the diameter of the disturbed region, referred to as $D_{\text {inner }}$, was also characterized.

Figure 8 shows that the evolution of both diameters $D_{\text {outer }}$ and $D_{\text {inner }}$ is similar to the removal depth and can be assigned directly to the removal regime. Within the regime II (disturbance-free removal) the cavity diameter $D_{\text {outer }}$ increases linearly with the laser power. For $d_{\text {spot }}=30.5 \mu \mathrm{m}$ the diameter $D_{\text {outer }}$ rises from (18 $\pm 0.2) \mu \mathrm{m}$ up to $(56 \pm 2.6) \mu \mathrm{m}$ within a laser power increase of $0.4 \mathrm{~W}$, while $D_{\text {outer }}$ increases from $(55 \pm 1.2) \mu \mathrm{m}$ to $(140 \pm 4.5) \mu \mathrm{m}$ with $d_{\text {spot }}=109 \mu \mathrm{m}$. Moreover, the transition to the disturbed removal regime III is characterized by a change in the slope increase of $D_{\text {outer }}$. Both, $D_{\text {outer }}$ and $D_{\text {inner }}$ continue then growing with a linear trend indicating thereby that the growth in width of the mushroom-like structures is also linear to a further increase of laser power.

\section{Discussion}

\subsection{Limit Temperatures of Laser Chemical Removal}

As mentioned before, the laser chemical machining is a temperature-driven 

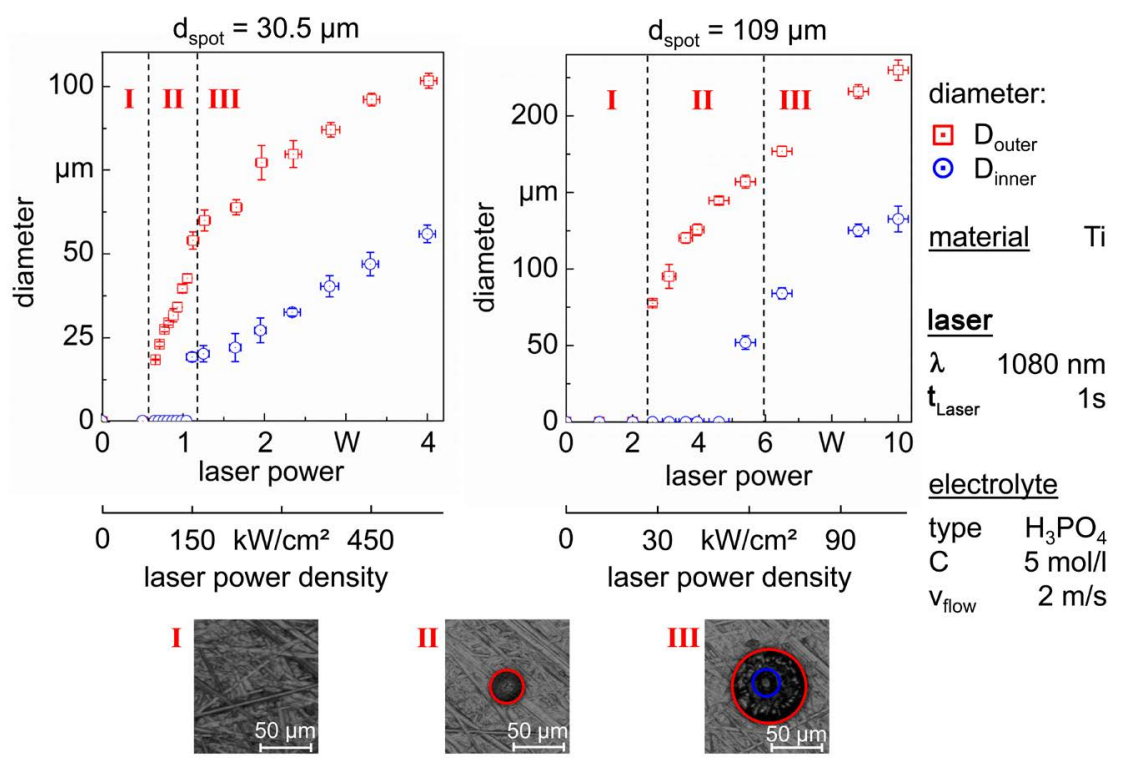

Messaoudi 2017

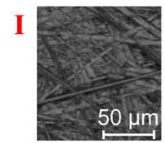

BIAS ID 171591

Figure 8. Measured characteristics diameters $D_{\text {outer }}$ and $D_{\text {inner }}$ in dependence of the applied laser power in titanium. $D_{\text {outer }}$ and $D_{\text {inner }}$ represent respectively the diameters of the removal cavity and the disturbed zone.

process, for which it is still a lack in understanding the direct correlation between the resulting removal geometry and the laser-induced temperatures.

From the validation of the model presented in Section 3 with the experimental results it is expected to open up the opportunity to:

1) Determine the required limits surface temperatures for a disturbance-free material removal.

2) Predict the resulting removal quality in dependence of the main process parameters, which can help to reduce the experimental expenditure.

Therefore, the temperature distribution has to be correlated spatially with the removal profiles of machined cavities, respectively with both distinctive diameters $D_{\text {outer }}$ and $D_{\text {inner }}$ (see the schematic diagram in Figure 9). It has to be noticed that $T_{R, \min }$ and $T_{R, \max }$ correspond to the bottom and upper limit temperatures at a defined parameter combination resulting in a successful material removal. At the regime II (disturbance-free removal) $T_{R, \min }$ represents the surface temperature at the distance $D_{\text {outer }} / 2$, whereas $T_{R, \max }$ is equal to the modelled peak laser induced surface temperature $T_{\text {model,peak }}$. Within the regime III (disturbed removal) $T_{R, \text { min }}$ and $T_{R, \max }$ correspond to the surface temperatures at the distances $D_{\text {outer }} / 2$ and $D_{\text {inner }} / 2$, respectively.

In Figure 10 the characteristic limits temperatures related to both diameters $D_{\text {outer }}$ and $D_{\text {inner }}$ are illustrated as a result of a laser irradiation $\left(t_{L}=1 \mathrm{~s}\right)$ with $d_{\text {spot }}=30.5 \mu \mathrm{m}$ and $d_{\text {spot }}=109 \mu \mathrm{m}$. It is observed that the laser chemical removal in the disturbance-free regime starts at a nearly constant temperature. With $d_{\text {spot }}=30.5 \mu \mathrm{m}$ the $T_{R, \min }$-plateau was found to range between $63^{\circ} \mathrm{C}$ and $66^{\circ} \mathrm{C}$, whereas this plateau lies between $68^{\circ} \mathrm{C}$ and $70^{\circ} \mathrm{C}$ with $d_{\text {spot }}=109 \mu \mathrm{m}$. As the titanium 
Regime I
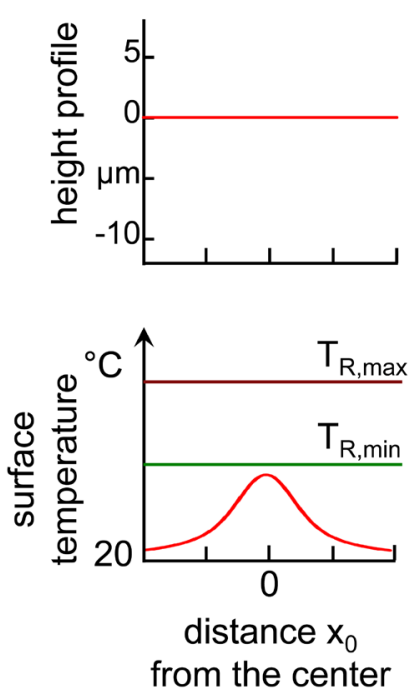

$\underline{\text { Regime II }}$

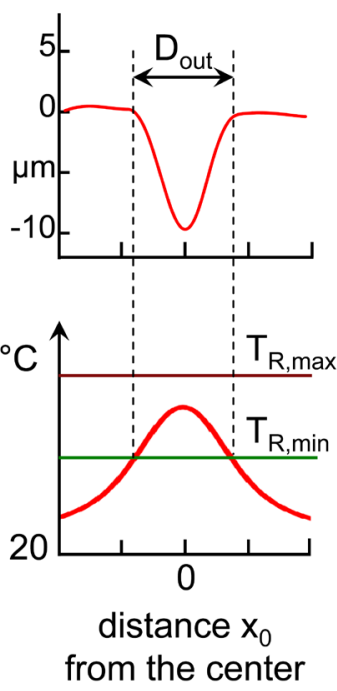

Regime III

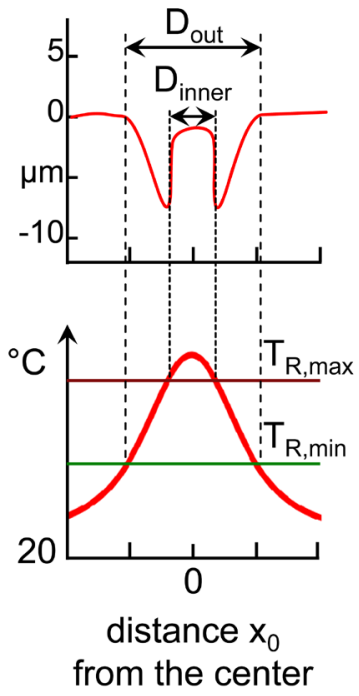

Messaoudi 2017

BIAS ID 171592

Figure 9. Schematic illustration of the spatial correlation between removal profile and temperature distribution at the workpiece surface. Using the geometric parameters $D_{\text {outer }}$ and $D_{\text {inner }}$ the temperature range for a disturbance-free laser chemical removal can be defined. Changes of the temperature distribution due to occurring disturbances in regime III are not taken into account.
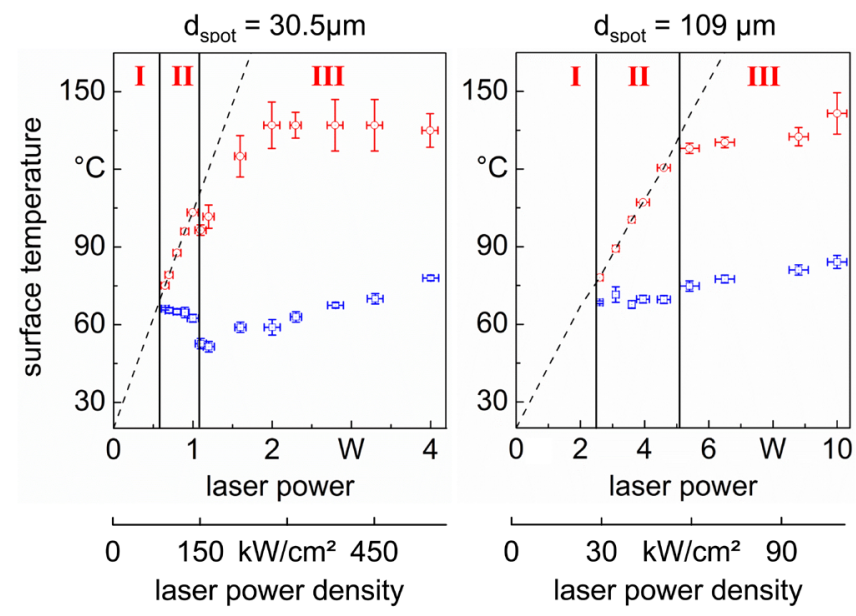

temperature:

๑ $T_{R, \min }$

$\odot T_{R, \max }$

-.. $T_{\text {model,peak }}$

material $\mathrm{Ti}$

laser

$\lambda \quad 1080 \mathrm{~nm}$

$t_{\text {Laser }} \quad 1 \mathrm{~s}$

removal regime: I no removal II non disturbed III disturbed

Messaoudi 2017

BIAS ID 171593

Figure 10. Defined bottom and upper limit surface temperatures $T_{R, \min }$ and $T_{R, \max }$ required for the laser chemical removal in titanium with a laser spot diameter of $30.5 \mu \mathrm{m}$ (left) and $109 \mu \mathrm{m}$ (right). The dashed lines depict the modeled peak surface temperature with consideration of heat losses into the electrolyte.

surface cannot undergo an interaction with the electrolyte at room temperature $\left(T \approx 20^{\circ} \mathrm{C}\right)$ it becomes clear that the activation of the anodic dissolution reaction requires a minimum limit temperature. 
Within the regime II it can be observed that the peak surface temperature represents the upper limit for the laser chemical removal. This is reflected on the linear increase of the temperature range with respect to the laser power. Moreover, as seen in Figure 10, the removal disturbances occur first at temperatures of about $108^{\circ} \mathrm{C}$ and $125^{\circ} \mathrm{C}$ with spots diameters of $30.5 \mu \mathrm{m}$ and $109 \mu \mathrm{m}$, respectively. In contrast to De Silva et al. [5], which have declared that the highest removal efficiency is achieved at surface temperatures $\approx 90^{\circ} \mathrm{C}$, the here defined upper limit temperatures $T_{R, \max }$ are higher. As discussed in [19], the water vaporization is mainly responsible for the primary bubble formation when water is irradiated by a micrometic heat source. The subsequent bubble expansion is then caused by the diffusion of dissolved gases. This confirms that the bubble formation and attachment, which characterize the disturbed regime, are strongly initiated by the electrolyte boiling.

The defined temperatures $T_{R, \max }$ in the regime III $\left(108^{\circ} \mathrm{C}\right.$ and $\left.125^{\circ} \mathrm{C}\right)$ are higher than the given boiling temperature of $104^{\circ} \mathrm{C}$ under $1 \mathrm{~atm}$. When considering the Nukiyama boiling curve it can be stated that these temperatures are related to the nucleate boiling. For aqueous solutions, this boiling regime extends from $5 \mathrm{~K}$ to about $30 \mathrm{~K}$ above the saturation temperature (here $104^{\circ} \mathrm{C}$ ) and is characterized by an enhanced bubble formation and an increasing heat flux [20]. Thus, taking the boiling temperature of the electrolyte as the upper limit guaranties a disturbance-free removal.

With a further increase of laser power in the removal regime III it can be seen that the upper limit temperature $T_{R, \max }$ achieve its maximum at $137^{\circ} \mathrm{C} \pm 5^{\circ} \mathrm{C}$. With respect to the boiling regime, this temperature range fits well to the transition boiling, in which the rate of bubble formation exceeds the rate of bubble detachment at the heated surface. Within this boiling regime a combined unstable vapor film with partial-nucleate boiling can be formed [20]. This leads to a decreased contact between the heated surface and the liquid solution and provides the evidence of the shielding model [9] that described the effect of an attached gas bubble on the quality of laser chemical machining of metals.

However, it has to be noticed that the presented model considers only constant heat transfer coefficient and does not reflect the temperature dependent heat flux within the different boiling regimes.

\subsection{Correlation between Surface Temperatures and Material Removal}

In Figure 11, the direct correlation between the defined limit temperatures and the removal characteristics (depth and diameter $D_{\text {outer }}$ ) is illustrated. Within the disturbance-free removal (regime II) a linear dependence on the applied laser powers is observed. As the upper limit temperature $T_{R, \max }$ and thereby the temperature range increases, the removal depth as well as the cavity diameter follow this trend and grow linearly. The observed maximum removal depths amount between $8 \mu \mathrm{m}$ and $11 \mu \mathrm{m}$ with both laser spot diameters. This is in accordance 

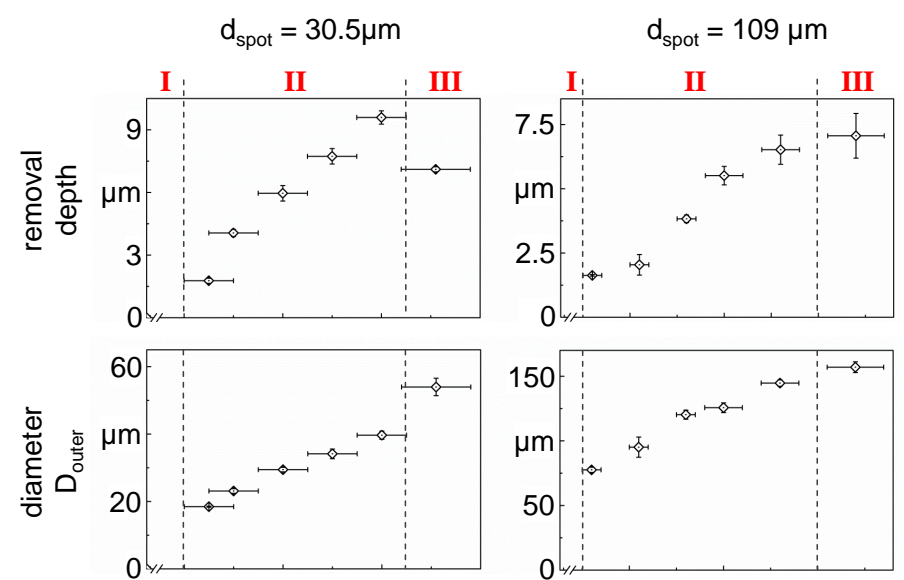

material

Ti

laser

$\lambda \quad 1080 \mathrm{~nm}$

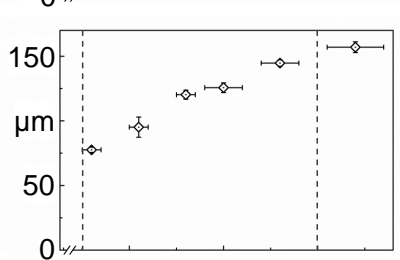

Laser $\quad 1 \mathrm{~s}$
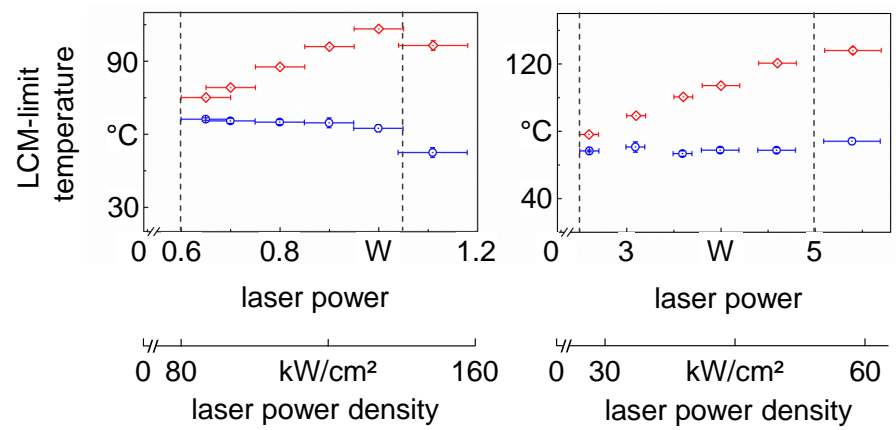

electrolyte

type $\quad \mathrm{H}_{3} \mathrm{PO}_{4}$

C $\quad 5 \mathrm{~mol} / \mathrm{l}$

flow $\quad 2 \mathrm{~m} / \mathrm{s}$

Messaoudi 2017

removal:

I no removal

II non disturbed

III disturbed

Figure 11. Direct correlation between the LCM-temperature range (blue color for $T_{R, \min }$ and red color for $T_{R, \max }$ ) and the removal dimensions (cavity depth and diameter) after a $1 \mathrm{~s}$-laser irradiation with $d_{\text {spot }}=30.5 \mu \mathrm{m}$ and $d_{\text {spot }}=109 \mu \mathrm{m}$.

with the maximum removal rate of $10 \mu \mathrm{m} / \mathrm{s}$ that was identified by Nowak et al. for the purely laser chemical machining of metals [6].

Furthermore, within the transition to the disturbed removal (formation of the mushroom-like structures) the slope-increase of $T_{R, \max }$ changes. As depicted in Figure 11, $T_{R, \max }$ switches to lower values than the expected peak temperatures $T_{\text {model,peak }}$. This affects directly the removal depth and cavity diameter. These show also a different growth slope when disturbances occur. Similar is observed also within the removal regime III. The formed mushroom-like structures follow the linear trend of the limit temperatures $T_{R, \max }$ until an observed maximum temperature plateau about $137^{\circ} \mathrm{C} \pm 5^{\circ} \mathrm{C}$ is achieved (see Figure 10). In contrast, the removal depth and cavity diameter remain increasing. For that reason, the removal rate cannot be anymore correlated to the surface temperatures. The occurring mechanisms in this regime are mainly dominated by the formation and attachment of gas bubbles.

Another interesting feature is the similar maximum values of the upper limit temperature $T_{R, \max }$ obtained with both laser spot diameters. This indicates the direct correlation between the surface temperatures, the laser power as well as the laser spot diameter. Taking into account Equation (13) it can be noted that the surface temperature is proportional to the ratio $P_{L} / d_{\text {spot. }}$. To verify this relation, the modeled peak surface temperatures as well as the experimentally identi- 
fied limit temperatures $T_{R, \min }$ and $T_{R, \max }$ are plotted as function of $P_{L} / d_{\text {spot }}$ for both laser spot diameters, as illustrated in Figure 12.

Thereby, a quasi-invariant evolution trend is observed with both spot diameters. $T_{\text {model,peak }}, T_{R, \min }$ and $T_{R, \max }$ show a characteristic and unique trend regardless the heated area. The observed deviation in $T_{\text {model,peak }}$ at temperatures greater than $100^{\circ} \mathrm{C}$ can be explained by the included heat losses when considering an enforced water boiling $\left(H=50.000 \mathrm{~W} / \mathrm{m}^{2} \cdot \mathrm{K}\right.$ for $\left.T_{\text {model,peak }}>90^{\circ} \mathrm{C}\right)$, which become more significant with an increased laser spot diameter (see Figure 5 ). In contrast, the deviations in $T_{R, \min }$ and $T_{R, \max }$ are related to the characterized diameters (see Figure 8) and range between $< \pm 5^{\circ} \mathrm{C}$ in the removal regime II and $<20^{\circ} \mathrm{C}$ in the disturbed removal regime.

From Figure 12 it can be stated that the laser chemical machining is governed by a two-dimensional heating process as the surface temperature is the determinant factor. Regardless the laser spot diameter the thermal evolution of the LCM-limit temperature is unique for a defined electrolyte-metal combination. Similar has been observed for the case of a $\mathrm{cw}$ laser heating of water in the front of a glass substrate containing gold nanoparticles. Here, Baffou et al. have reported that the gas bubble formation is generated in the superheating regime at temperatures of about $220^{\circ} \mathrm{C}$ independent of the applied laser spot diameter [21].

Thus, the quotient $P_{L} / d_{\text {spot }}$ can be used as an indicator to predict the removal quality. In Table 2, the LCM-removal regimes of titanium in a $5 \mathrm{~mol} / \mathrm{l}$ are illustrated. Thereby, a disturbance-free removal is assured regardless the laser spot size at $P_{L} / d_{\text {spot }}$ ranging between $23 \mathrm{~mW} / \mu \mathrm{m}$ and $40 \mathrm{~mW} / \mu \mathrm{m}$.

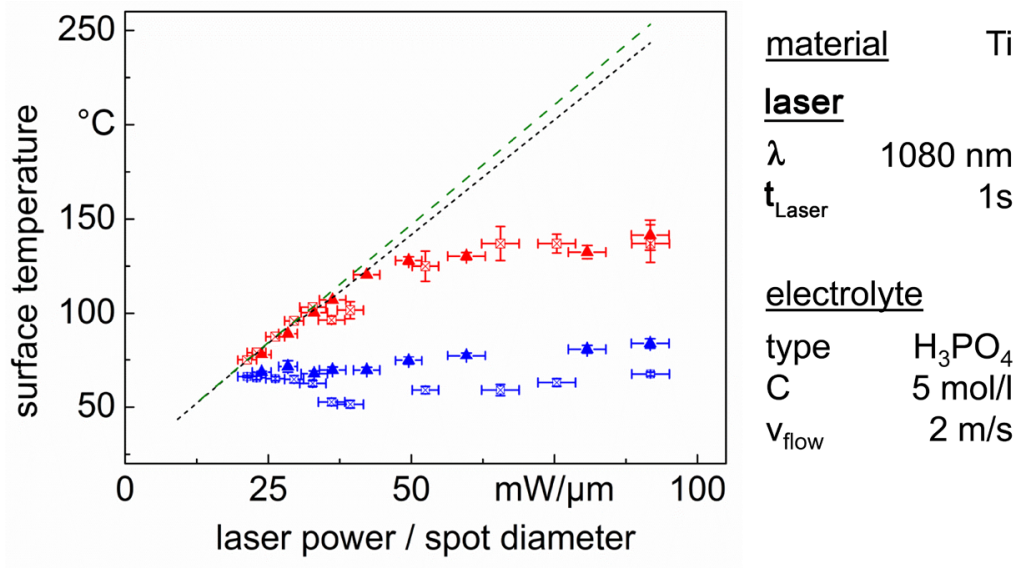

\begin{tabular}{|c|c|c|c|}
\hline & $T_{R, \text { min }}$ & $\mathrm{T}_{\mathrm{R}, \max }$ & $\mathrm{T}_{\text {model,peak }}$ \\
\hline $\mathrm{d}_{\mathrm{spot}}=30.5 \mu \mathrm{m}$ & 漓 & 漓 & --- \\
\hline$d_{\text {spot }}=109 \mu \mathrm{m}$ & 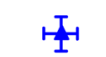 & I & ----- \\
\hline
\end{tabular}

Messaoudi 2017

BIAS ID 171595

Figure 12. LCM-limit temperatures $T_{R, \min }$ and $T_{R, \max }$ and modeled peak surface temperature $T_{\text {model,peak }}$ as a function of the ratio $P_{L} / d_{\text {spot }}$ obtained with both laser spot diameters $30.5 \mu \mathrm{m}$ and $109 \mu \mathrm{m}$. The correlation shows a quasi-invariant evolution trend. 
Table 2. Removal quality of titanium in $\mathrm{H}_{3} \mathrm{PO}_{4}$ in dependence of the quotient $P_{L} / d_{\text {spot }}$.

\begin{tabular}{cccc}
\hline Removal regime & $\begin{array}{c}\text { (regime I) } \\
\text { No removal }\end{array}$ & $\begin{array}{c}\text { (regime II) } \\
\text { Disturbance-free removal }\end{array}$ & $\begin{array}{c}\text { (regime III) } \\
\text { Disturbed removal }\end{array}$ \\
\hline$P_{L} / d_{\text {spot }}[\mathrm{mW} / \mu \mathrm{m}]$ & $<23$ & $23 \cdots 40$ & $>40$ \\
\hline
\end{tabular}

It has to be noticed that the influence of the reaction time, which is also an important factor, is not studied in this work. This will be included in a following second part, in which the laser chemical removal will investigated under consideration of a moving laser beam with different feed velocities.

\section{Conclusions}

In this work a Green-function based modeling of the laser-induced temperatures at the workpiece surface during the laser chemical machining was presented. From its correlation with resulting removal geometry following conclusions can be drawn:

1) The initiation of a laser chemical removal requires a minimum threshold temperature. This ranges between $63^{\circ} \mathrm{C}$ and $70^{\circ} \mathrm{C}$ when processing titanium in phosphoric acid.

2) The enhanced gas bubble formation within the nucleate boiling of the electrolyte defines the upper limit of the laser chemical removal. This is in line with the experimental observations.

3) Within the disturbance-free processing regime the material removal show a linear behavior. Both, removal depth and cavity diameter follow the linear increase of the surface temperature with respect to the applied laser power.

4) The limit surface temperatures of a laser chemical machining follow a unique and invariant evolution regardless the size of the heated area. This is only dependent on the material-electrolyte-combination.

In a next step the thermal modeling will be extended to the case of a moving laser beam, in which the influence of the reaction time will be investigated depending on the feed velocity. The provision of a temperature-dependent formulation of the material load will open up the opportunity of comparing the laser chemical machining with other thermal- and chemical-based processes such as electrochemical and electro discharge machining.

\section{Acknowledgements}

The authors would like to thank the German Research Foundation (Deutsche Forschungsgemeinschaft) for funding the subprojects A5 "Laserkontur" within the Collaborative Research Center (SFB 747) and F07 "Lasersignatur" within the Transregional Collaborative Research Center (CRC/TRR 136) at the University of Bremen.

\section{References}

[1] Vollertsen, F., Biermann, D., Hansen, H.N., Jawahir, I.S. and Kuzma, K. (2009) Size Effects in Manufacturing of Metallic Components. CIRP Annals-Manufacturing 
Technology, 58, 566-587.

[2] Hsu, T.-R. (2002) Miniaturisation-A Paradigm Shift in Advanced Manufacturing and Education. IEEE/ASME International Conference on Advanced Manufacturing Technologies and Education in the 21 st Century, Chia-Yi, 10-15 August 2002, 1-19.

[3] Stephen, A. and Vollertsen, F. (2010) Mechanisms and Processing Limits in Laser Thermochemical Machining. Annals of the CIRP, 59, 251-254.

[4] Stephen, A., Lilienkamp, T., Metev, S. and Sepold, G. (1999) Laser-Assisted Micromachining of Large-Area 3DMetallic Microparts. In: McKeown, P. and Corbett, J., Eds., Proceedings of the 1 st International Conference of the European Society for Precision Engineering and Nanotechnology, Shaker Verlag, Aachen, 20-23.

[5] De Silva, A.K.M., Pajak, P.T., McGeough, J.A. and Harrison, D.K. (2011) Thermal Effects in Laser Assisted Jet Electrochemical Machining. CIRP Annals-Manufacturing Technology, 60, 243-246.

[6] Bäuerle, D. (2011) Laser Processing and Chemistry. 2nd Edition, Springer Verlag, Berlin Heidelberg. https://doi.org/10.1007/978-3-642-17613-5

[7] Nowak, R. and Metev, S. (1996) Thermochemical Laser Etching of Stainless Steel and Titanium in Liquids. Applied Physics A, 63, 133-138. https://doi.org/10.1007/BF01567640

[8] Weikert, M., Fohl, C., Dausinger, F. and Abeln, T. (2003) Surface Structuring of Metals with Short and Ultra Short Laser Pulses. SPIE, 5063, 208-213.

[9] Mehrafsun, S. and Vollertsen, F. (2013) Disturbance of Material Removal in Laser-Chemical Machining Bye Merging Gas. Annals of the CIRP, 62, 195-198.

[10] Mehrafsun, S., Messaoudi, H. and Vollertsen, F. (2016) Influence of Material and Surface Roughness on Gas Bubble Formation and Adhesion in Laser-Chemical Machining. Proceedings of the 5 th International Conference on Nanomanufacturing, Macau.

[11] Butt, H.-J., Graf, K. and Kappel, M. (2003) Physics and Chemistry of Interfaces. Wiley-VCH, Weinheim.

[12] Yavas, O., Oltra, R. and Kerrec, O. (1994) Enhancement of Pulsed Laser Removal of Metal Oxides by Electrochemical Control. Applied Physics A, 63, 321-326. https://doi.org/10.1007/BF01567320

[13] Grigoropoulos, C.P. (2009) Transport in Laser Microfabrication. Cambridge University Press, Cambridge. https://doi.org/10.1017/CBO9780511596674

[14] Carslaw, H.S. and Jaeger, J.C. (1959) Conduction of Heat in Solids. 2nd Edition, Oxford University Press, New York.

[15] Yung, E.K., Hussey, B.W., Gupta, A. and Romankiw, L.T. (1989) Laser Assisted Etching of Manganese-Zinc-Ferrite. Journal of Electrochemical Society, 136, 665-673. https://doi.org/10.1149/1.2096707

[16] Ren, C. and MacKenzie, A.R. (2007) Closed-Form Approximations to the Error and Complementary Error Functions and Their Applications in Atmospheric Science. Atmospheric Science Letters, 8, 70-73. https://doi.org/10.1002/asl.154

[17] Eckert, S., Messaoudi, H., Mehrafsun, S. and Vollersten, F. (2017) Laser-Thermo-Chemical Induced Micro-Structures on Titanium. Journal of Materials Science and Surface Engineering.

[18] Whitelaw, J.H. (2011) Convective Heat Transfer, Thermopedia: Guide to Thermodynamics, Heat \& Mass Transfer, and Fluids Engineering. https://doi.org/10.1615/AtoZ.c.convective_heat_transfer 
[19] Deguchi, S., Takahashi, S., Hiraki, H. and Tanimura, S. (2013) Direct Measurement of Force Exerted during Single Bubble Generation. Applied Physics Letters, 102, Article ID: 084101. https://doi.org/10.1063/1.4793532

[20] Faghri, A., Zhang, Y. and Howell, J.R. (2010) Advanced Heat and Mass Transfer. Global Digital Press, Columbia, 665-734.

[21] Baffou, G., Polleux, J., Rigneault, H. and Monneret, S. (2014) Super-Heating and Micro-Bubble Generation around Plasmonic Nanoparticles under CW Illumination. The Journal of Physical Chemistry C, 118, 4890-4898.

https://doi.org/10.1021/jp411519k 


\section{Supplementary Materials}

Table A1. List of used symbols.

\begin{tabular}{|c|c|c|}
\hline Symbol & Description & Unit \\
\hline$A$ & Laser beam area at the surface & $\mathrm{m}^{2}$ \\
\hline$a$ & Approximation constant [16] & - \\
\hline$C_{p}$ & Specific heat capacity & $\mathrm{kJ} /(\mathrm{kg} \mathrm{K})$ \\
\hline$D$ & Thermal diffusivity & $\mathrm{m}^{2} / \mathrm{s}$ \\
\hline$D_{\text {inner }}$ & Inner removal diameter & $\mu \mathrm{m}$ \\
\hline$D_{\text {outer }}$ & Outer removal diameter & $\mu \mathrm{m}$ \\
\hline$d_{\text {spot }}$ & Laser spot diameter & $\mu \mathrm{m}$ \\
\hline$G$ & Green function & - \\
\hline$H$ & Heat transfer coefficient & $\mathrm{W} /\left(\mathrm{m}^{2} \cdot \mathrm{K}\right)$ \\
\hline$I$ & Laser power density & $\mathrm{W} / \mathrm{cm}^{2}$ \\
\hline 1 & Absorption depth & $\mathrm{nm}$ \\
\hline$P_{L}$ & Laser power & $\mathrm{W}$ \\
\hline$P_{a b s}$ & Absorbed laser power & $\mathrm{W}$ \\
\hline$r$ & Laser beam radius & $\mu \mathrm{m}$ \\
\hline$T$ & Temperature rise & ${ }^{\circ} \mathrm{C}$ \\
\hline$T_{\text {Boiling }}$ & Electrolyte boiling temperature & ${ }^{\circ} \mathrm{C}$ \\
\hline$T_{\text {model,peak }}$ & Peak surface temperature (Model) & ${ }^{\circ} \mathrm{C}$ \\
\hline$T_{R, \max }$ & Upper limit temperature for a material removal & ${ }^{\circ} \mathrm{C}$ \\
\hline$T_{R, \min }$ & Bottom limit temperature for a material removal & ${ }^{\circ} \mathrm{C}$ \\
\hline$t$ & Time & s \\
\hline$t_{L}$ & Irradiation time & s \\
\hline v & Feed velocity & $\mathrm{m} / \mathrm{s}$ \\
\hline$X Y Z$ & Dimensionless coordinates & - \\
\hline$x y z$ & Dimensional coordinates & $\mathrm{m}$ \\
\hline$\alpha$ & Dimensionless quantity $(r / I)$ & - \\
\hline$\alpha_{a b s}$ & Wavelength related absorption coefficient of $T_{i}$ & $\%$ \\
\hline$\theta$ & Dimensionless quantity $(H \cdot r / \kappa)$ & - \\
\hline$\kappa$ & Thermal conductivity & $\mathrm{W} /(\mathrm{m} \mathrm{K})$ \\
\hline$\lambda$ & Laser wavelength & $\mathrm{nm}$ \\
\hline$\phi$ & Integration variable/substitution quantity $(\tau-\tau)$ & - \\
\hline$\rho$ & Density & $\mathrm{Kg} / \mathrm{m}^{3}$ \\
\hline$\tau$ & Dimensionless time coordinate & - \\
\hline$\tau_{E}$ & Transmission coefficient of the electrolyte & $\%$ \\
\hline$\Psi$ & Dimensionless temperature rise & - \\
\hline
\end{tabular}



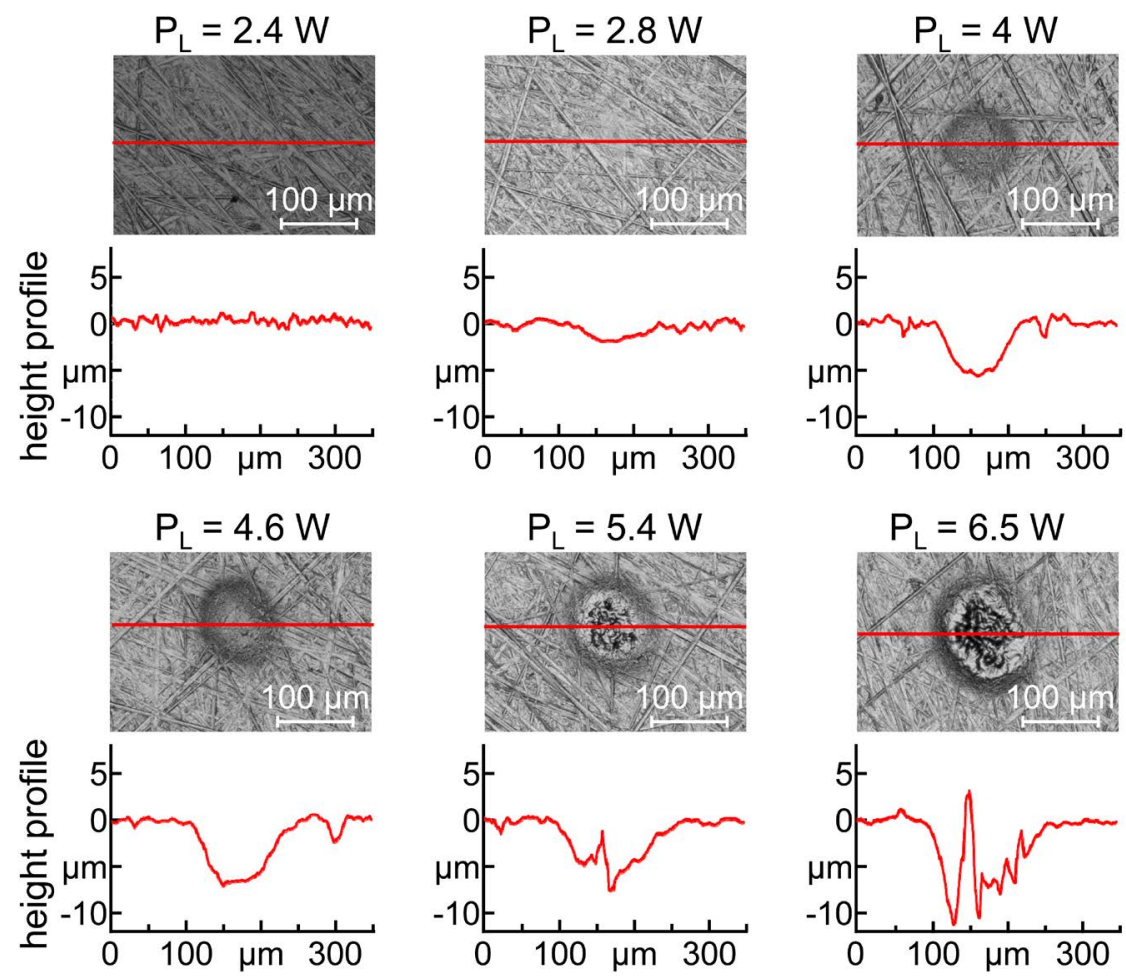

Messaoudi 2017

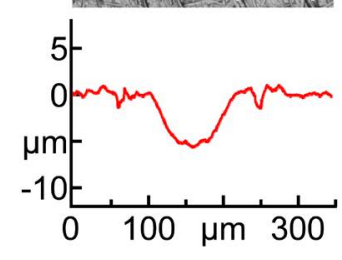

Figure A1. Microscopic images of the removal spots and their height profiles in dependence of the applied laser power after a $1 \mathrm{~s}$-irradiation with a $109 \mu \mathrm{m}$ laser spot.

\section{Scientific Research Publishing}

Submit or recommend next manuscript to SCIRP and we will provide best service for you:

Accepting pre-submission inquiries through Email, Facebook, LinkedIn, Twitter, etc. A wide selection of journals (inclusive of 9 subjects, more than 200 journals)

Providing 24-hour high-quality service

User-friendly online submission system

Fair and swift peer-review system

Efficient typesetting and proofreading procedure

Display of the result of downloads and visits, as well as the number of cited articles

Maximum dissemination of your research work

Submit your manuscript at: http://papersubmission.scirp.org/

Or contact msa@scirp.org 